\title{
Population and labour force projections for 27 European countries, 2002-2052: impact of international migration on population ageing
}

Projections de population et de population active pour 27 pays européens 2002-2052: impact de la migration internationale sur le vieillissement de la population

\author{
Jakub Bijak · Dorota Kupiszewska · Marek Kupiszewski • \\ Katarzyna Saczuk • Anna Kicinger
}

Received: 8 August 2005/ Accepted: 31 March 2006/Published online: 2 March 2007

(C) Springer Science+Business Media B.V. 2007

\begin{abstract}
Population and labour force projections are made for 27 selected European countries for 2002-2052, focussing on the impact of international migration on population and labour force dynamics. Starting from single scenarios for fertility, mortality and economic activity, three sets of assumptions are explored regarding migration flows, taking into account probable policy developments in Europe following the enlargement of the EU. In addition to age structures, various support ratio indicators are analysed. The results indicate that plausible immigration cannot offset the negative effects of population and labour force ageing.
\end{abstract}

Keywords Population projections · Labour force projections · International migration - Population ageing · Europe

Résumé Des projections de population et de population active sont présentées pour 27 pays Européens pour la période 2002-2052, avec un intérêt particulier pour l'impact de la migration internationale sur la dynamique des populations. A partir de scénarios uniques pour la fécondité, la mortalité et l'activité économique, trois séries d'hypothèses concernant les flux migratoires sont explorées, en intégrant des prévisions sur les développements des politiques publiques à la suite de l'élargissement de l'Union Européenne. Les structures par âge sont analysées, de même que des indicateurs de rapports de dépendance. Les résultats indiquent que les flux d'immigration vraisemblables ne pourront pas compenser les effets négatifs du vieillissement de la population et de celui de la population active.

J. Bijak $(\bowtie) \cdot$ D. Kupiszewska $\cdot$ M. Kupiszewski $\cdot$ K. Saczuk $\cdot$ A. Kicinger

Central European Forum for Migration Research, ul. Twarda 51/55,

00-818 Warsaw, Poland

e-mail: j.bijak@cefmr.pan.pl 
Mots-clés Projections de population - Projections de population active · Migration internationale $\cdot$ Vieillissement de la population $\cdot$ Europe

\section{Introduction}

This study presents the results of the projections of population and labour force resources for 27 selected European countries for the period 2002-2052, focussing on the impact of international migration on the advancement of the population ageing process. The analysis covers 27 selected European countries: 23 EU countries without Cyprus and Malta, 2 EFTA countries: Norway and Switzerland, as well as 2 acceding countries: Bulgaria and Romania. The study thus only includes countries with over one million inhabitants, an exception being made for Luxembourg due to its central location in Europe and important position in the European migration system. Three EU candidate countries (Croatia, the former Yugoslav Republic of Macedonia and Turkey, as of 1 January 2006) have not been considered in the analysis due to very high political uncertainty regarding the dates and conditions of their possible accession.

The projections have been prepared under various assumptions concerning international migration, referred to as Base, High and Low. The Base set of assumptions is the one likely to occur according to our judgement, while the other two reflect our opinion about the plausible highest and lowest boundaries of future migration developments. The analysis has been performed using the MULTIPOLES (MULTIstate POpulation model for multiLEvel Systems) population dynamics model developed by Kupiszewski and Kupiszewska (1998). Extensive supporting material for this study, including a thorough discussion of the assumptions and detailed country-specific results, can be found in a number of papers (Bijak 2004; Bijak, Kupiszewska, Kupiszewski, \& Saczuk 2005; Bijak, Kupiszewski, \& Kicinger 2004; Saczuk 2004), downloadable from the website www.cefmr.pan.pl.

In addition to the 'Introduction', the paper comprises five sections. Section 2 presents the background for the study: selected theoretical aspects of population and labour force ageing, as well as some empirical evidence with respect to the magnitude of these phenomena in Europe. Section 3 contains brief remarks on the input data used in the projections, the applied model of population dynamics, as well as the assumptions on the future development of fertility, mortality, international migration and labour force participation in Europe. The population and labour force projections are presented in Sects. 4 and 5, respectively. Finally, Sect. 6 offers a brief summary of the outcome of the study, as well as the most important conclusions and policy recommendations.

Though there is a distinction between the terms 'projection' and 'forecast', and our Base scenario may be considered as a forecast, we will use the term 'projection' for both forecasts and projections, for the sake of simplicity.

Throughout the paper, the terms 'economically active population' and 'labour force' conform to the definition depicting the overall labour supply i.e. both the employed and unemployed. This is a different category than the 'working-age population' assumed to be the overall number of people between 15 and 64 years of age. Activity rates (also: labour force participation rates) relate the number of the 
active to the overall size of the population (cf. International Labour Organisation 2004). The terms 'economic activity' and 'labour force participation' are used interchangeably.

\section{Background: population and labour force ageing in Europe}

Population ageing is a "process, by which older individuals become a proportionally larger share of the total population" (United Nations 2002, p. 1). Ageing is a consequence of low fertility and the related low family size, as well as longer life expectancy, and is additionally influenced by international migration. Contemporarily, this process seems to be permanent and irreversible (Coleman 2002).

Ageing recently became a very important policy issue, as it has wide-ranging implications in various areas of social, economic and political life. The most important side-effects of the ageing process include (United Nations 2002, pp. 1-3):

- increasing public expenditure on pensions, social security and health services, caused directly by the growing number of elderly (and thus of pensioners) in the population;

- a decreasing percentage of people in the working age, causing a shrinkage of the labour force and an increase in the overall burden on the working population in terms of various intergenerational transfers: taxes, other contributions, family support etc.;

- increasing risk of failure of repartition (pay-as-you-go) pension systems;

- growing demand for medical care and changing public health patterns (even though the elderly become relatively fitter and healthier);

- increasing risk of the emergence of intergenerational conflicts, due to the changes in the patterns of resource distribution between the generations.

Although the mentioned problems are not critical yet, the policy-makers must realise that to overcome the possible future consequences of ageing, appropriate measures should be implemented soon. This is a very important policy challenge, embracing many areas of life: economy, social security systems, health care, education, changes in the attitudes and practices towards the elderly etc. (cf. European Commission 2005; Grant et al. 2004; National Research Council 2001; Productivity Commission 2005). There seems to be no feasible, exclusively demographic solution to population ageing, and the remedies for its negative effects need to be sought among non-demographic policies (Coleman 2002).

There have been attempts to consider immigration as a partial measure against the effects of ageing, originating from the mathematical demographic models of Pollard (1973) and Espenshade, Bouvier, and Arthur (1982), who showed that under certain conditions immigration leads to a stationary population with a stable age structure. Recently, the 'replacement migration' idea has been explored in a study by Feld (2000), as well as in a United Nations (2000) report, the latter having been extensively discussed (Coleman 2002; Espenshade 2001; Lesthaeghe 2000; and others, see Saczuk 2003 for an overview). Studies on 'replacement migration' indicate that the number of immigrants required in order to sustain certain parameters of population structures would have to be very high. Therefore, reasonable migration flows can influence the age structure of the host population only to a limited extent, fertility being much more important in that respect, especially in the long run. Korcelli (2003) also noted 
that because of this 'replacement migration' cannot be used as a tool for designing national migration policy. The current study aims at formulating plausible migration ranges for the 27 selected European countries and assessing their impact on the ageing of the population and the labour force.

There are many measures that may quantify the magnitude of the impact of ageing on population and labour force structures. With respect to the former, a commonly used measure is the Potential Support Ratio (PSR), indicating how many people aged 15-64 in a given population can potentially support one person aged 65 years or more. The age limits of 15 and 65 years, dividing the population into the pre-working, working and retirement age groups, have been set for all the countries under study for the sake of comparison with the United Nations (2000) report. It is worth noting that alongside the interval of 15-64 years, the 20-59 or 20-64 age intervals are frequently used in similar studies (e.g. Augusztinovics 1999).

Measures like the PSR and its reciprocal (the old-age dependency ratio), are widely used in research on ageing, but they are only a rough indication of the impact of the process on the economic situation of the societies. In order to take into account not only changes in the age structure of the population, but also in the labour force participation, we propose two additional measures: the Economic Elderly Support Ratio (EESR) and the Labour Market Support Ratio (LMSR).

Let EESR be defined as the ratio of the whole economically active population aged 15 years or more to the inactive population in the retirement age (65 years or more). Thus, such a measure is a proxy of the economic burden of inactive pensioners on the working population, and is therefore an important indicator of the effects of ageing from the point of view of sustainability of the pension systems. Further, let LMSR be defined as the ratio of the whole economically active population to the whole inactive population, where both the nominator and the denominator consider people of 15 years or more. This indicator can be interpreted as a proxy of the overall economic burden of the inactive population on the labour market. LMSR is thus more general than EESR, as it considers not only the pensioners, but also younger inactive generations (excluding children), both of which have to be economically supported by the active population.

It is worth noting that similar measures have already been used in a number of studies. An equivalent of a reciprocal of the EESR is often referred to as the System Dependency Ratio (SDR), defined as "the ratio of those receiving pension benefits to those accruing pension rights" (OECD 2005). The EESR is by necessity more simplistic than the SDR due to fixed age limits of working and retired populations in the former measure, the latter being flexible with respect to the age of retirement (UN ECE 1999, p. 46). Indicators similar to LMSR and its reciprocal are referred to as for example 'the economic support ratio' (Tomorrow's Company 2005) or 'the economic burden' (Taylor 2003).

The process of ageing in Europe has been progressing substantially in the second half of the 20th century. Eurostat and Council of Europe data imply that the average PSR for the 27 countries under study decreased from 6.49 in 1960 to 4.19 in 2002 and that the country-level variation in the magnitude of ageing measured by the PSR is strongly interrelated with past fertility changes. The average EESR indicates that in 2002 each economically inactive person in the 65+ age group corresponded to 3.09 active persons. The mean LMSR of 1.30 for the same year denotes a heavy burden of the economically inactive on the active population. 
In 2002 the PSR ranged from 3.55 for Italy, 3.77 for Sweden and 3.86 for Belgium to 5.49 for Poland, 6.09 for Ireland and 6.11 for the Slovak Republic. As concerns the economic burden of pensioners on the active population, the EESR varied from 2.21 for Italy, 2.55 for Belgium and 2.62 for Bulgaria to 4.30 for the Slovak Republic, 4.52 for Ireland and 5.59 for Romania. The exceptionally good position of Romania is primarily due to the broad definition of the economically active population combined with a strong income effect in this country (Saczuk 2004). With respect to the labour market burden measured by LMSR, in 2002 the best situation was observed in Switzerland (2.06), Denmark (1.99) and Norway (1.96), while the worst in Bulgaria (1.03), Hungary (0.96) and Italy (0.88). In the two latter countries, the economically inactive have already outnumbered the active population. Countryspecific values of all three indicators are presented in Tables 3 and 5 in further parts of this paper.

In terms of the advancement of population ageing and its negative economic and labour market effects in Europe, the situation of Italy is clearly the worst, due to very low fertility and labour force participation. Ageing processes and their negative labour market consequences are also fairly advanced in Belgium, Bulgaria and Hungary. On the other hand, a relatively good situation with respect to a combination of various support ratios can so far be observed in Denmark, the Netherlands, Switzerland, Portugal, Ireland and the Slovak Republic; in the first four countries mainly due to the high economic activity rates, while in the latter two- to the young population structures.

The current analysis aims to contribute to the debate on ageing, by providing population and labour force projections for the 27 selected European countries for the period 2002-2052, conditional on the demographic situation, in particular the magnitude of migratory flows in the area under study. The existing projections of population include for example US Census Bureau (2004), World Bank (2005), United Nations (2005) and Eurostat (2005), and with respect to the labour force and economic aspects, Coleman (1992), Roseveare, Leibniz, Fore, and Wurzel (1996) and Feld (2000). In our study the analysis focuses on the impact of international migration on the aggregate indicators of population ageing, as well as pension systems and labour market burdens. Specific features of the current research include: (1) improved, more detailed treatment of international migration; (2) formulating assumptions on policy developments in Europe following the EU enlargement; (3) analysis of projected social security burdens in terms of proposed aggregate measures, the EESR and the LMSR; (4) analysis of sensitivity of the results to fertility and economic activity assumptions.

The analysis of the sensitivity of the results to the retirement age is deliberately omitted in the current study, as it has already been considered elsewhere (United Nations 2000). We consider our approach to be more complete than the one based solely on raising the legally defined retirement age. In the current study, some economic activity improvement beyond the age of 65 years is assumed, which is reflected in the EESR and LMSR indicators. Moreover, the retirement age of 65 years is already significantly higher than the actual (not official) retirement ages observed recently in almost every European country (UN ECE 1999, p. 47). Therefore, the assumption about the upper limit of the working age at 65 years can to a certain extent accommodate for the future increase in the real age at retirement. 


\section{Data, model and projection assumptions}

\subsection{Data sources used in this study}

In quantitative terms, this analysis is based on demographic data from the official statistical registration of population, births, deaths and migratory events in the countries under study, collected by Eurostat and the Council of Europe. Data on labour force participation have been taken from the database of the International Labour Organisation (2004). Five-year groups of age are used: for population stocks and mortality for ages $0-84$ years and $85+$, for fertility by age of mother within the range 15-49 years and for economic activity for ages 15-74 and 75+.

Migration flows have been estimated as the higher of the values reported by the sending and receiving countries. Their age schedules have been predominantly assumed to be the same as in the case of migration between Germany and a particular country, due to the limitations imposed by incomplete country-specific statistics on migration by age. Germany has been selected as a reference for age schedules due to the completeness of data and a significant share in European migration flows. The exceptions are: migration to the Mediterranean, where the age distributions have been estimated from the data of the receiving countries, and countries of Central and Eastern Europe, where average schedules of migration between Germany and all European countries have been applied.

Details concerning the sources used, the methodology of verification of their quality, as well as their preparation for input into the projection model can be found in the respective background papers on demographic, migration and labour participation scenarios (Bijak 2004; Bijak et al. 2004; Saczuk 2004).

\subsection{MULTIPOLES model of population dynamics-general remarks}

The population projection model applied in this study, MULTIPOLES, was originally created by Kupiszewski and Kupiszewska (1998) basing on the ideas of P.H. Rees (Rees 1996; Rees, Stillwell, \& Convey 1992). The MULTIPOLES model was constructed according to the modelling paradigm set out by Rogers (1975). It is a cohort-component female-dominated, multi-regional, multi-country model. The population is disaggregated into two sexes, 18 -year age groups (i.e. 19 projection cohorts, with the cohort number 0 being the birth cohort and the cohort $85+$ being the last one), as well as countries and regions (but the regional dimension has not been used in this study). The model is based on the movement type population accounts, which use counts of migration moves during a period, as recorded for example by population registration systems. For a discussion of movement type accounts and alternative transition type accounts (which look at the location of migrants at the beginning and the end of a projection period) see Rees and Willekens (1981).

Occurrence-exposure rates appearing in the MULTIPOLES accounts are defined as the number of events (deaths, migration or births) in a projection period divided by the population at risk, calculated as an arithmetic average of the population of the projection cohort at the beginning and at the end of the projection period. International migration is handled on two geographical levels. The first level involves population exchange between the countries under study, while the second level 空 Springer 
depicts migration between each of the countries and the Rest of the world (countries outside the group of 27 countries, considered together).

Below, the main projection equations of the MULTIPOLES model have been presented. For simplicity, matrix notation has been used, and sex, region and country indexes have not been shown explicitly. There are three different equations: for the birth cohort, for the oldest open-ended cohort, and for the other cohorts, formulated as follows:

$$
\begin{gathered}
\boldsymbol{P}_{0}(t+u)=\boldsymbol{F}_{00}(t, t+u)\left[\boldsymbol{B}(t, t+u)+\boldsymbol{M}_{\mathrm{EXT} 00}(t, t+u)\right] \\
\boldsymbol{P}_{A+}(t+u)=\boldsymbol{S}_{A+}(t, t+u) \boldsymbol{P}_{A+}(t)+\boldsymbol{F}_{A+}(t, t+u) \boldsymbol{M}_{\mathrm{EXT} A+}(t, t+u)+ \\
\boldsymbol{S}_{A-u}(t, t+u) \boldsymbol{P}_{A-u}(t)+\boldsymbol{F}_{A-u}(t, t+u) \boldsymbol{M}_{\mathrm{EXT}(A-u)}(t, t+u) \\
\boldsymbol{P}_{a+u}(t+u)=\boldsymbol{S}_{a}(t, t+u) \boldsymbol{P}_{a}(t)+\boldsymbol{F}_{a}(t, t+u) \boldsymbol{M}_{\mathrm{EXT} a}(t, t+u)
\end{gathered}
$$

where

$$
\begin{gathered}
\boldsymbol{S}_{a}(t, t+u)=\left[\boldsymbol{I}+0.5 \boldsymbol{M}_{a}(t, t+u)\right]^{-1}\left[\boldsymbol{I}-0.5 \boldsymbol{M}_{a}(t, t+u)\right], \\
\boldsymbol{F}_{a}(t, t+u)=\left[\boldsymbol{I}+0.5 \boldsymbol{M}_{a}(t, t+u)\right]^{-1} .
\end{gathered}
$$

$\boldsymbol{I}$ is the identity matrix and $\boldsymbol{M}_{a}(t, t+u)$ is a matrix dependent on death rates, internal emigration rates and on international emigration rates (for flows to the 27 European countries).

The meaning of the indexes in the formulas (1-5) is as follows: $u$-span of the age groups and the length of a projection step; $t$-time; $a$-age group (covering persons at the age from $a$ to $a+u$ years); 00-the birth cohort; $A+-$ the oldest, open-ended age group, covering persons of age $A$ or more. The stock variables are:

$$
\begin{array}{ll}
\boldsymbol{P}_{a}(t) & \text { Population in age group } a \text { at time } t \text {, that means at the beginning } \\
& \text { of a projection step } \\
\boldsymbol{P}_{a}(t+u) \quad \text { Population in age group } a \text { at time } t+u \text {, that means at the end of a } \\
\text { projection step }
\end{array}
$$

The event variables are:

$\boldsymbol{B}(t, t+u) \quad$ - Births over the period $(t, t+u)$;

$\boldsymbol{D}_{a}(t, t+u) \quad$ - Deaths in age group $a$ over the period $(t, t+u)$;

$\boldsymbol{M}_{\mathrm{EXT} a}(t, t+u)$ - Net migration from the Rest of the world ('external migration') in age group $a$ over the period $(t, t+u)$

In MULTIPOLES, fertility and mortality are modelled using age-specific occurrence-exposure rates, albeit the assumptions on future development of both components of natural change of the populations under study are prepared, respectively, in terms of total fertility rates (TFR) and life expectancy at birth $\left(e_{0}\right)$, 
as described further in Sects. 3.3 and 3.4. For fertility, although it is a factor potentially influenced by international migration, we assume that migrants adjust to the fertility patterns of the host population, which is supported for example by the recent findings of Kulu (2005). The same applies to mortality, where this assumption can be justified by migrants gaining access to health care services at destination, and being exposed to the same environmental hazards as the host population.

In addition to modelling and projecting the overall population change, the MULTIPOLES model allows for including assumptions on future labour force participation trends, and is therefore also suitable for labour force projections. For practical use, the model has been programmed as specialised computer software, developed and continuously improved by D. Kupiszewska, since 1996. A thorough description of the model is available in Kupiszewski (2002), as well as Kupiszewska and Kupiszewski (2005). The model and the software have been recently re-designed specifically for the purpose of the current study.

\subsection{Fertility assumptions}

The societal changes that have occurred in developed countries since the 1960 s and now seem to be durable, resulted in below-replacement fertility levels. A variety of explanations of these trends have been offered, for example the hypothesis of fertility adjustment to the relative well-being of particular cohorts (Easterlin 1968), the theory of the second demographic transition (Lesthaeghe \& van de Kaa 1986), or the economic analysis of opportunity costs of childbearing (Becker 1991). Thus, a return to the replacement-level fertility in the future cannot be feasibly assumed, especially given strong processes of individualisation that have been taking place in Europe, although the possibility of further changes in societal values cannot be excluded.

There is no evidence that any single policy measure can significantly reverse or stop fertility decline. As noted by Grant et al. (2004), given different contexts of fertility (social, economic, political etc.), only a blend of various types of intervention has a chance to work in the long run. Muszyńska (2006), corroborating the ideas presented by Liefbroer and Corijn (1999), noted that not only socially supported (policy-related), but also socially accepted (in a normative sense) arrangements for the reconciliation of a career and family life have an impact on fertility. This supports the notion of van de Kaa (2003) that fertility decline can be reversed for example through perceiving childbearing as a way of self-realisation of the parents, a process that is likely to happen first in Western Europe, and with a time delay in the other parts of the continent. The economic and institutional settings may become involved, but primarily as additional influencing factors rather than the main determinants of the fertility trend. In any case, some increase of period fertility levels in Europe is expected, primarily due to the recuperation of the childbearing postponed in the past (Sobotka 2004).

Therefore, the fertility scenario assumes a short-term continuation of past trends in the total period fertility rates (TFR) and their slight increase in the longer term. The target values for 2052 reflect to a large extent the current diversity of childbearing patterns across Europe, as well as the level of advancement of particular countries in the process of the second demographic transition. Thus, the bottom end of the target TFR values assumed for 2052 is 1.4 for Bulgaria and Romania, and 1.5

Springer 
for Central Europe, Southern Europe, as well as for the German-speaking countries, with the exception of Estonia (1.6) and Portugal (1.7). By 2052, the countries with a relatively high fertility are assumed to be Belgium, Luxembourg and the United Kingdom (TFR of 1.8), as well as France, Ireland, the Netherlands and all the Scandinavian countries (1.9). These assumptions, presented in Table 1, thus reflect a lack of convergence of fertility patterns in Europe. It is worth noting that the target TFR values are not very far from the ones assumed by Eurostat (2005) for 2050, differing on average only by 0.02 children per woman, with the biggest difference for the Netherlands (1.75 in the Eurostat's projection as compared to 1.9 in the current one).

\subsection{Mortality assumptions}

The question of the limits of human longevity has always been a very controversial issue among demographers and epidemiologists. All theoretical limits to life expectancy (e.g. Olshansky, Carnes, \& Cassel 1990) have been subsequently surpassed by real-life developments, which were not usually foreseen by population forecasters (Oeppen \& Vaupel 2002). As argued by Christensen and Vaupel (1996), only a quarter of the variation in the length of life in the developed countries can be attributed to genetic factors and thus there is still much left to improve from the medical, behavioural and environmental side.

With a certain dose of optimism it is assumed that although one cannot exclude the emergence of new infectious diseases, their impact on public health in the developed countries will likely be offset by technological, institutional and behavioural changes. As a result, the maximum life expectancy observed worldwide is envisaged to continue increasing, although at a declining pace, unlike in the linear hypothesis of Oeppen and Vaupel (2002). For Western Europe, one can expect a visible convergence of the trends, both to the maximum level and also within this group of countries. For Central and Eastern Europe, however, only a slow convergence towards the highest values can reasonably be assumed, due to large initial disparities in comparison with most developed countries. Due to institutional, economic and social circumstances it will undoubtedly take the post-socialist countries many more years to recover in terms of mortality improvements, although the recent trends already indicate an upturn from the post-transformation crisis (Meslé 2004).

With regard to mortality scenarios, the highest life expectancy at birth in 2052 is expected for the Western European countries, in particular for Switzerland, Italy, Spain, France, Scandinavian countries, Austria, Germany and the Benelux. The projected values for these countries are very close to the maximum ones, assumed to equal ca. 85 years for males and 90 years for females. Among the European countries under study, the lowest values are envisaged for the Baltic States, Bulgaria and Romania. The minimum life expectancy for males projected for 2052 is the one for Latvia (76 years), while for females - the one for Romania (83 years). Additionally, a decline of the life expectancy gap between males and females is assumed for all the countries under study. Detailed country-specific assumptions for 2052 are presented in Table 1 and thoroughly discussed in Bijak (2004).

\subsection{International migration assumptions}

The assumptions on international migration for the countries under study have been done differently for two categories of flows, following Kupiszewski (2002). Migration 


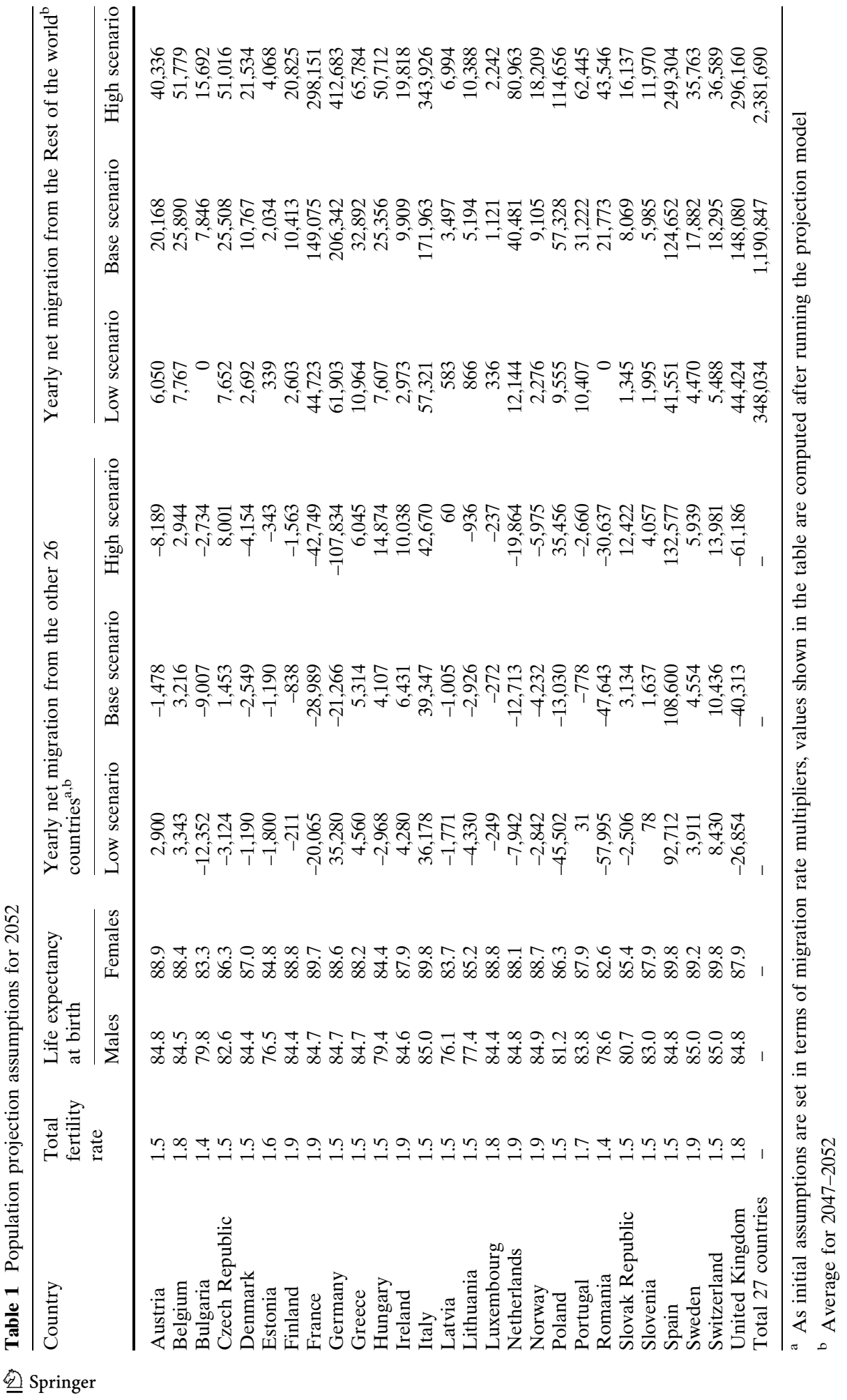


among the 27 countries has been quantified in terms of emigration rates per 1,000 population of the source country (specified separately for each direction of flow). Setting the assumptions in terms of migration rates rather than crude numbers allows to capture the propensity to migrate more adequately and to avoid problems with the artificial acceleration of depopulation in the countries with a negative population growth. The scenarios of migration exchange with the Rest of the world ('external migration') concern crude net migration numbers, as in this case it is hardly possible to define the population at risk to which the observed migration flows can be related. For both categories of flows various sets of assumptions (scenarios) have been formulated, based on the qualitative analysis of migration factors.

When preparing the scenarios of net international migration from the Rest of the world, the economic and political situation at the fringes of the enlarged EU has been considered, including the former USSR, the former Yugoslavia, Turkey, the Maghreb countries, as well as other important sending regions, like China. It is foreseen that inflows to Europe will continue regardless of the pace of the socioeconomic development in the countries of origin. Existing disparities in income and living conditions between Europe and most of the outside world will constitute, among other determinants, a strong pull factor to migrate. An overview of macroeconomic determinants of migration has been recently presented by Jennissen (2004), who identified income differences per capita and unemployment as the most important factors. On the other hand, policy measures aimed at limiting migration or shaping it in a desired way, like attracting highly skilled professionals, are almost certainly going to be implemented. Other important migration factors, including political crises, armed conflicts, environmental problems etc. have not been considered in setting the scenarios, due to the unpredictability of both their timing and magnitude of their impact on population flows. For this reason, the presented scenarios focus on economic migrants and their family members rather than, for example, on asylum seekers.

The following three scenarios are envisaged:

- The Base scenario, with a sustained improvement of economic, political and social situation worldwide, resulting in a moderate, positive net inflow to Europe. Policy measures are assumed not to be restrictive, due to a relatively good and stable socio-economic situation in Europe.

- The Low scenario, assuming economic stagnation both in Europe and in the Rest of the world, the latter more important as a strong positive (encouraging) push factor, than the former as a negative (deterrent) pull factor. This combination would result in migration pressure on the developed countries, which would in this scenario be offset by restrictive migration policies. An overall effect would be a decline of net migration registered in the European countries.

- The High scenario, assuming dynamic economic growth and social development, resulting in a demand for foreign labour and thus leading to relatively liberal immigration policies. Economic growth in the developing regions is assumed to be a factor contributing to an increased mobility of people worldwide.

The Low and High scenarios are designed as upper and lower boundaries of a variety of possible, but not quantified here, future developments of international migration. For example, one can imagine a combination of high economic growth and strict migration policies, or low growth and liberal policies. Such (not very 
probable) scenarios would result in migration flows that would be in-between the ones projected in the Low and High variants. On the other hand, asymmetric growth in Europe and in other parts of the world would likely cause an adjustment of European migration policy measures to suit the aims of the receiving countries in the first place. In effect, the observed registered flows would also likely fit into the plausible span set by the Low and High scenarios.

Similar assumptions for the Base, High and Low scenarios are envisaged for population flows among the 27 countries under study, although with some alterations resulting from the gradual opening of the labour markets of the old EU-15 countries to the citizens of the new member states. Hence, the Base scenario assumes a stable, favourable socio-economic situation in Europe and a long-term convergence of income levels in all European countries. The first factor is expected to result in an overall increase in mobility following the increase of job opportunities abroad, while the latter in a reduction of income-related push factors to emigrate from Central and Eastern Europe to the West. The positive effects of European integration are likely to occur in full in the long term, which is going to intensify the returns of former emigrants. We also assume that, after the process of European integration with respect to freedom of movement of labour is completed, migration policies will not affect population movements within the enlarged EU.

The Low scenario envisages economic stagnation in Europe, with high unemployment levels and related structural labour market problems. With hardly any factors increasing the overall spatial mobility due to very slow income growth and few new job opportunities, the key factor shaping population movements in Europe is likely to be high migration pressure of Central and Eastern Europe on the West European countries.

In the High scenario, substantial economic growth and fast convergence of the economies and of the living standards are expected for all European countries, boosting the overall mobility within Europe and reducing the push factors to emigrate from the less developed regions, including Central and Eastern Europe.

The timing of the gradual liberalisation of the labour markets of the old EU-15 for the citizens of the new member states is framed by the Treaty on Accession signed in April 2004 (European Communities 2003). According to the Treaty, the old EU-15 countries were given the right to introduce transitory provisions for 2, 5 or maximally 7 years in order to limit the access to their labour markets for workers originating from the new member states. In 2004, only Ireland, Sweden and the United Kingdom did not introduce any such measures.

On the basis of the economic and political situation in the other EU-15 countries, a scenario of probable future dates of definitive opening of the labour markets has been set. Note that the assumptions presented here reflect a state of knowledge as of 2005 and that political decisions taken by particular countries may differ from the presented scenario. We assumed that Denmark, Finland and the Benelux countries, as well as Norway (a country of the European Economic Area and as such bound by the Treaty on Accession) are likely to open their labour markets for the new EU nationals in 2006. For them, the introduction of the transitional period was probably an insurance against the unpredictable effects of the enlargement rather than a necessity to protect their labour markets. The limited wave of post-accession migration to Ireland, Sweden and the UK, confirmed by statistics presented in a recent report by the European Commission (2006), can be an important factor encouraging the introduction of a full freedom of movement policy.

Springer 
The southern EU-15 countries: Italy, France, Spain, Portugal and Greece are less likely to open their labour markets in 2006 and judging by such economic factors as high unemployment rates, 2009 seems to be more probable in that respect. Germany and Austria are almost sure to extend the restrictions on access to their labour markets for the maximal period, until 2011, due to high unemployment, popularity of anti-immigrant slogans and the close proximity of the new member countries. Switzerland does not currently participate in the free movement of workers in Europe, although this will likely be gradually liberalised by 2007 for EU-15 citizens and by 2011 for the new member states (cf. DFA 2005; European Communities 2002). Bulgaria and Romania will join the EU in 2007 according to the Accession Treaty signed in April 2005 (European Communities 2005) and identical transitional provisions have been provided for them with regard to the free flow of workers. In this study it is assumed that Western European labour markets will open for Bulgarians and Romanians according to the similar schedule as above, but with a 3-year delay.

In general, an overall migration trend is assumed in all scenarios, with the gradual introduction of the freedom of movement policy marked through temporary deviations from the primary tendency, followed by returns of migration levels to their general trends in the long-term. Following the full implementation of the freedom of movement policy, the size and direction of migratory flows is going to depend heavily on the disparities between origin and destination countries.

The most important changes can be thus expected with respect to population flows from Central and South-Eastern to Western and Northern Europe. Their magnitude depends on differences in income between particular countries, as well as on the scenario type. With respect to eastward migration it is assumed that there will be an increase in population flows, yet rather limited in size. It is envisaged that labour movements between the old and new EU member states will increasingly become two-way flows, although the primary source of eastward migration will be the returns of earlier emigrants.

Numerically, scenarios of flows among the 27 countries multiply the initial origin-destination rates by factors consisting of two components: an overall trend (a constant level in the Low scenario, mobility increase by $0.5 \%$ yearly in the Base scenario and by $1 \%$ in the High one) and temporal deviations resulting from the labour market policies discussed above. 'External' migration scenarios are quantified using an exponential extrapolation from the 2002 values to the target ones, presented in Table 1. Details of qualitative assumptions, their quantification and target values of particular variables are given in Bijak et al. (2004).

In addition to migration scenarios mentioned above, the Status Quo projection has been prepared, assuming constant migration rates for flows between the 27 countries and constant crude net migration from the Rest of the world, the same as observed in 2002. The results are similar to those obtained for the Base scenario, with some country-level exceptions. The most notable include Spain, where constant immigration at 2002 level lowers the projected burden of the inactive persons in comparison to Base scenario throughout the projection period, as well as Poland, the Czech Republic and the Slovak Republic, where assumed constant net outflow of migrants increases this burden. The detailed results for the Status Quo scenario, not presented here, can be found in Bijak et al. (2005). 


\subsection{Labour force participation assumptions}

In the last 20 years rapid changes on the labour markets have been observed. Economic activity of women has increased substantially while that of older workers has decreased. These factors, combined with an evolution of social roles and institutional settings, resulted in an expansion of the share and position of women in the labour force. Motherhood still depresses female labour force participation, but in more and more countries the development of childcare services and social habits facilitate higher economic activity of women (European Commission 2003). In many countries under study e.g. Austria, Denmark, Sweden and Norway, the female participation patterns resemble the male one, only with slightly lower levels of agespecific participation rates.

It is expected that in the coming decades the economic activity of women will further increase. The process will be most noticeable for women aged 25-54 years and will be particularly dynamic in the countries with relatively low rates i.e. Italy, Spain and Greece. By 2052 all countries in the study should reach an inverted U-shaped pattern of female economic activity, with only small differences in levels of activity between the countries.

A drastic decline of participation in the oldest age groups has been related to the development of social security systems and the possibility of an earlier retirement. As the latter shall probably end soon, it is foreseen that the social security systems will be reorganised. New rules should create incentives to work longer with no breaks in careers, increasing the age-specific participation rates of older people. Encouragement to higher activity of older workers, however, should also come from the demand side of the market, involving flexible work schedules, part-time jobs etc. The latter would ensure that older people's willingness to work would not be confronted with poor employment prospects (Kotowska 2003).

Hence, it is envisaged that in 2052 the economic activity of older workers will be much higher compared to current levels in most of the countries. The current decade will, however, still be the time of the continuation of the country trends and only later the trends will start to converge to the assumed target values. If rapid changes of the economic activity of older workers are expected, they are assumed to take place around 2030. Despite the age-specific labour force participation rates for women being lower than those for men, scenarios for all the countries assume that the economic activity of older men and women should stabilise on the same level in the long run. The case of Finland, where the female participation rates in a few older age groups are higher than the male ones, demonstrates that such an assumption is not unrealistic.

A recent sharp decline of the economic activity of young people was the effect of technological progress which, creating demand for specific skills and knowledge, lifted up the value of education. Since the economic returns from additional years of schooling went up, ever more young people are engaging in different forms of education, which excludes market activity and lowers participation rates (Green, Owen, \& Wilson 2001).

Therefore, a continuation of past trends is expected in the current decade, which in many countries means a further decline of participation rates of the young. In this period particularly rapid declines will be observed in most Central and East European countries. It is envisaged, however, that the development of flexible forms of employment will enable the reconciliation of education with economic activity 
Table 2 Age-specific labour force participation rates assumed for $2052(\%)$

\begin{tabular}{|c|c|c|c|c|}
\hline \multirow[t]{2}{*}{ Age group } & \multirow[t]{2}{*}{ Males } & \multicolumn{3}{|c|}{ Females } \\
\hline & & Low participation ${ }^{\mathrm{a}}$ & High participation $^{\mathrm{b}}$ & $\begin{array}{l}\text { Central-Eastern } \\
\text { Europe }^{\mathrm{c}}\end{array}$ \\
\hline 15-19 & 40 & 30 & 40 & 30 \\
\hline $20-24$ & 75 & 65 & 65 & 65 \\
\hline $25-29$ & 93 & 75 & 80 & 75 \\
\hline $30-34$ & 95 & 80 & 85 & 85 \\
\hline $35-39$ & 95 & 80 & 85 & 85 \\
\hline $40-44$ & 95 & 80 & 85 & 85 \\
\hline $45-49$ & 95 & 80 & 85 & 85 \\
\hline $50-54$ & 90 & 75 & 75 & 75 \\
\hline $55-59$ & 70 & 60 & 60 & 60 \\
\hline $60-64$ & 40 & 40 & 40 & 40 \\
\hline $65-69$ & 25 & 25 & 25 & 25 \\
\hline 70-74 & 15 & 15 & 15 & 15 \\
\hline $75+$ & 5 & 5 & 5 & 5 \\
\hline
\end{tabular}

${ }^{a}$ Belgium, France, Greece, Ireland, Italy, Luxembourg, Portugal, Spain, Switzerland, United Kingdom

b Austria, Denmark, Finland, Germany, Netherlands, Norway, Sweden

c Bulgaria, Czech Republic, Estonia, Hungary, Latvia, Lithuania, Poland, Romania, Slovak Republic, Slovenia

and will allow for an increase of activity rates in the 15-24 age group after 2015 and their stabilisation on higher levels in the long run. In a few cases (especially in Northern European countries), due to exceptionally high current levels of labour force participation, the target values have been modified upwards (details in Saczuk 2004). The only group for which a stagnation or even a moderate decline in economic activity can be expected within the next 50 years are the middle-aged men.

Assumptions on the target age-specific labour force participation rates have been prepared separately for men (a common pattern for all countries under study) and for women (distinguishing three groups of countries according to their recent activity patterns: the high participation countries, the low participation countries and Central and Eastern Europe). A summary of the assumptions is presented in Table 2.

\section{Population projection results under various migration scenarios, 2002-2052}

\subsection{Base migration scenario}

Under the Base scenario, the overall population size of the 27 countries under study is hardly going to change over the next 50 years: from the initial 494.2 million in 2002, to 494.9 million half a century later (Table 3). However, this stability is to a large extent owing to immigration from other parts of the world. Between 2002 and 2052, 58.5 million people net are assumed to immigrate to the countries under study (on average 1.2 million persons yearly). Should only natural change and migration between the countries under study be considered, the 2052 population of the 27 countries would be smaller by $16 \%$.

Important changes that are likely to concern European countries in the coming 50 years are related to the shifts in age structures as a consequence of the 


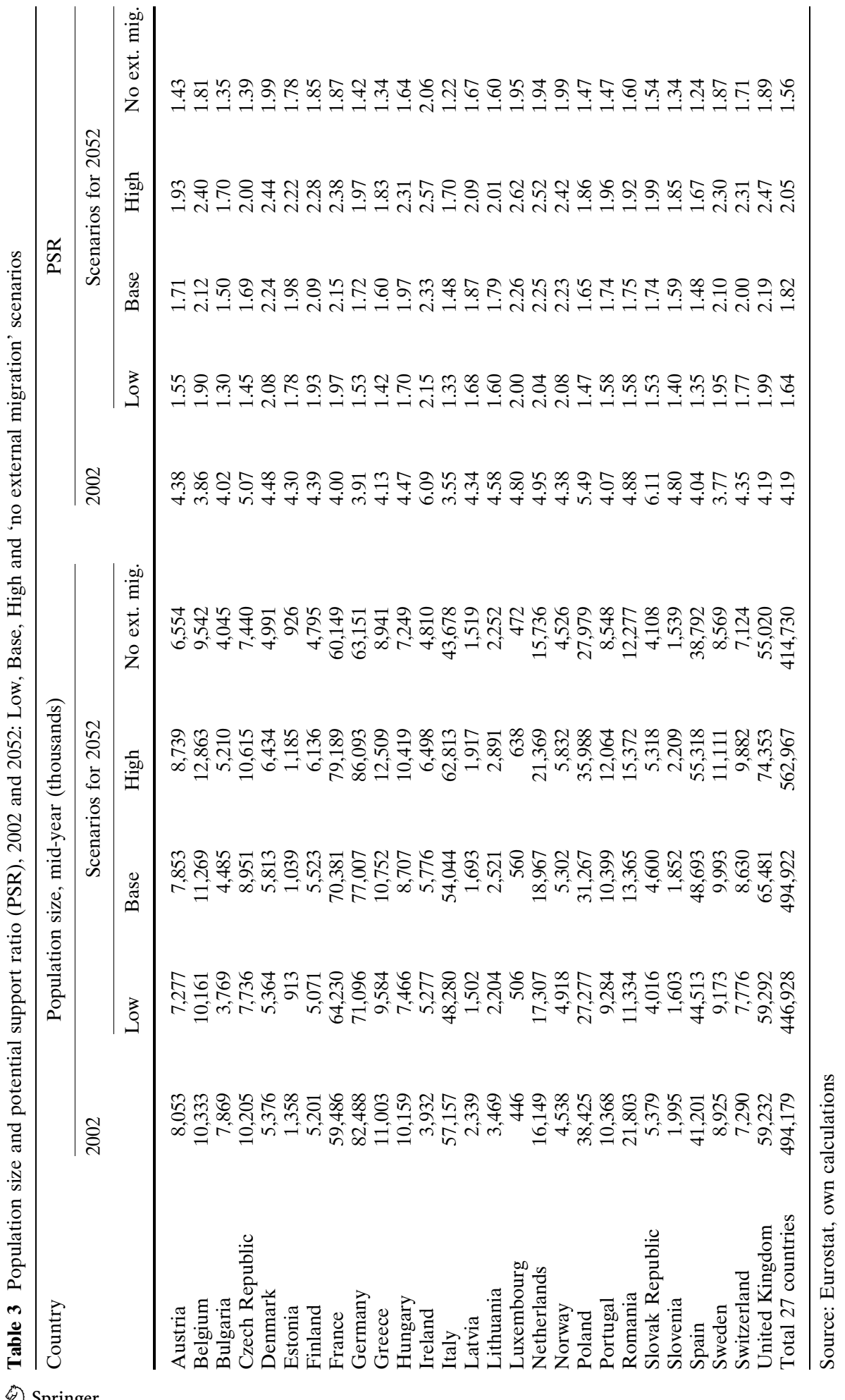


advancement in population ageing. A visible decline in the number and proportion of young people is expected, combined with an increase in the older age groups, including the oldest-old ( 85 years or more). The most numerous age group is predicted to shift from 35-39 years of age in 2002 to 60-64 years 50 years ahead.

A comparison of age pyramids for the countries under study in 2002 and 2052 is presented in Fig. 1. The pyramids for 2052 graphically distinguish the demographic structures of the population already present in the countries under study in 2002 and their descendants ('original' population, no shading), and those of the post-2002 immigrants and their descendants ('newcomers', shading depending on the scenario). To differentiate between the two structures, an auxiliary simulation of population developments has been used, assuming no migration from the Rest of the world.

The advancement of ageing can also be seen in terms of aggregate measures assessing its impact on population. The PSR is expected to decrease from 4.19 persons in the working age (15-64) per one aged 65+ in 2002 to 1.82 in 2052. On the country level, the PSR values projected for 2052 vary from 1.48 for Italy and Spain to 2.33 for Ireland (see Table 3 ). The other countries where the ageing process is going to be relatively little advanced over the next half a century, are the ones with relatively high-fertility levels. This especially concerns Luxembourg, the Netherlands, Denmark and Norway. On the other extreme are the countries of Southern and South-Eastern Europe, including (in addition to Italy and Spain) Bulgaria, Slovenia and Greece. This overview shows that the degree of projected ageing is strongly diversified among the countries under study and primarily concerns Southern and Central-Eastern Europe.

The presented results are comparable with the outcome of the recent Eurostat (2005) population projections. The Base population projected for 2052 (excluding Norway and Switzerland, not covered by the latter analysis) is only by $2 \%$ higher than the one projected by Eurostat for 2050 in its baseline variant. Some minor country-level differences are mainly due to different assumptions on international migration. The projected PSR values are also similar, especially on the European level.

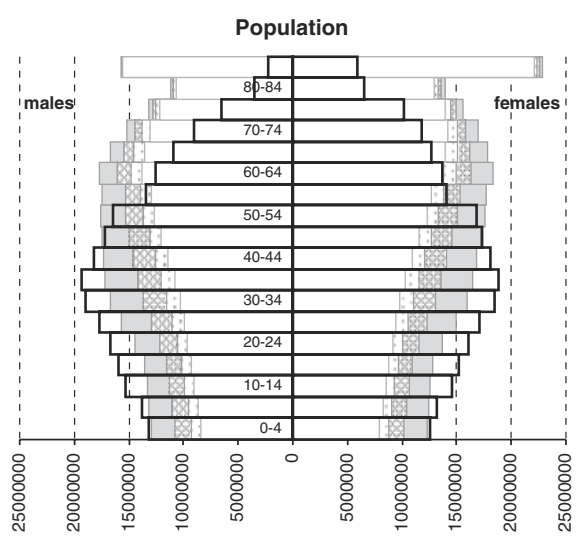

$\square$ High (2052) $⿴$ Base (2052) $\square$ Low (2052) $\square$ No ext. mig. (2052) $\square 2002$

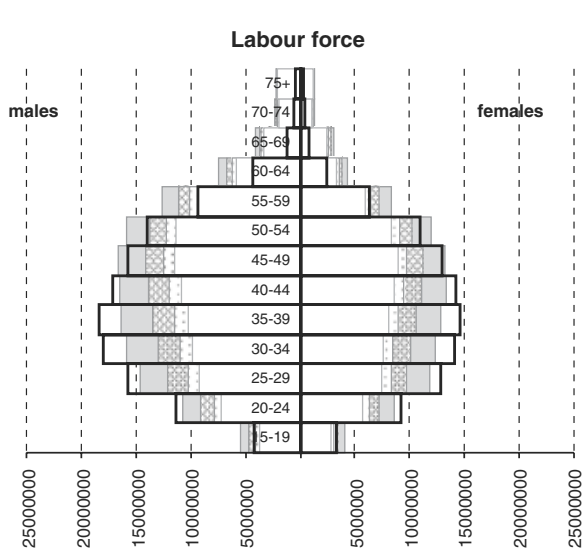

$\square$ High (2052) 匹 Base (2052) $\square$ Low (2052) $\square$ No ext. mig. (2052) $\square 2002$

Fig. 1 Population and labour force age pyramids of the 27 countries, 2002 and 2052-Base, Low, High and 'no external migration' scenarios. Source-Eurostat, own calculations 


\subsection{High and Low migration scenarios}

Under the High scenario assumptions, the total population size of all the countries under study is going to increase by $14 \%$ during the projection period, from 494 million in 2002 to 563 million in 2052. Over 50 years, about 109 million people net are assumed to come as immigrants to the 27 European countries, on average 2.2 million yearly.

The shifts in the age structures expected in the High scenario are similar to those in the Base one, yet with proportionally more immigrants and their descendants in all age groups. The impact of increased immigration can be seen here as a more moderate decline in the proportion of the younger generations, as well as a more gentle increase in the share of the older age groups, including the oldest-old. Thus, due to the inflow of more immigrants, who are relatively younger than the receiving population, the ageing process in the High projection variant is slightly less advanced than in the Base one. The average PSR in 2052 is expected to equal 2.05, ranging from 1.67 for Spain and 1.70 for Italy and Bulgaria to 2.57 for Ireland and 2.62 for Luxembourg.

Under the conditions assumed in the Low scenario, the overall population size of the 27 European countries is envisaged to decline to 447 million in 2052, that is by $10 \%$, mainly due to limited immigration from the other parts of the world not being able to balance out low fertility. During the whole period 2002-2052, the total number of 'external' immigrants to the 27 countries under study in the Low scenario is expected to be only about 22.8 million people net, thus on average less than half a million a year.

The projected changes in the age structures in the countries under study resemble the ones obtained for the Base scenario, although with proportionally less immigrants observed in all the age groups. Reduced immigration streams result in more rapid ageing of the populations. The age pyramid is much slimmer, with more advanced relative decline in the proportion of the younger generations in the population (see Fig. 1). The average PSR in the Low variant is expected to reach 1.60, ranging between 1.30 for Bulgaria and 2.15 for Ireland.

The span between the High and Low scenarios regards therefore not only the estimated final population and the labour force size of the 27 countries, but also more importantly, the age structures and thus the advancement of the ageing process with its economic consequences, as indicated in Fig. 1. These differences are almost exclusively due to the impact of immigration of generally younger people from the Rest of the world.

\section{Labour force projection under various migration scenarios, 2002-2052}

\subsection{Base migration scenario}

This section describes the projections of the future labour force, i.e. the overall labour supply comprised of both employed and unemployed, estimated by weighting the total size of the working-age population (aged 15-64 years) by age-specific economic activity rates. According to the Base scenario, the overall labour supply of the 27 countries will decline by almost $10 \%$, from 233 million people in 2002 to 210 million 50 years later. In 2052, immigrants and their descendants are going to ac- 
count for one-fifth of the total labour force. The overall economic activity rate for population aged 15 years or more is expected to decrease from $57 \%$ in 2002 to $49 \%$ in 2052. This is a direct result of the projected demographic change, which is much stronger than the assumed increase in age-specific labour force participation rates. The country-specific figures for the overall labour force, as well as for the $15+$ labour force participation rates for 2002 and 2052 are presented in Table 4.

Apart from the changes in the size, significant shifts in the age structures of the labour force are expected. In particular, the shares of the middle-age groups are going to decrease. The proportion of the young age groups (15-24) in the labour force will remain almost the same in 2052 as in 2002 (about 12\%). The most significant changes can be foreseen for the older age groups $(65+)$, for which both the size and the proportion in the total labour force is going to increase more than 3 times. This is a combined result of the assumed increase in the labour force participation of older people, and the projected increase of the share of persons aged $65+$ in the total population. The growing significance of the older age groups in the total labour force will no doubt require developing institutional facilities encouraging their active participation in the labour market.

Changes in population and labour force structures projected for 2052 are also reflected in the EESR and the LMSR indicators defined in Sect. 2, i.e. the measures of the overall burden of ageing on social security systems and on the labour force. In the 27 European countries, the EESR is expected to decline on average from 3.09 in 2002 to 1.51 in 2052. The LMSR is predicted to decrease from 1.30 to 0.95 . Without migration exchange with the other parts of the world, these values would be even smaller.

On the country level, a diversity of the projected labour force structures and their changes can be observed in Europe, with the most visible consequences of ageing in Southern and Central-Eastern Europe and relatively more modest in the North. The country-specific values of the EESR and the LMSR for 2002 and 2052 are presented in Table 5. Additionally, Figs. 2, 3 and 4 illustrate the Base scenario changes of the PSR, the EESR and the LMSR, respectively (note different bar scales used in the three figures).

At the end of the projection period, the order of countries ranked by the EESR and the LMSR values is very similar to their ranking by fertility levels, modified by the labour force participation patterns (more so in the case of the LMSR) and only with a very limited effect of the advancement of the ageing process prior to 2002 . Notably, the relatively high ranks of Central and Eastern European countries at the beginning of the projection period are mostly due to the young population structures. In total, 50 years ahead, these countries loose their favourable position, mainly as a result of the pertaining low-fertility levels. In the Scandinavian countries the opposite is the case: their population structure was regressive already in 2002. The relatively high fertility and economic activity levels during the whole projection period place them at the top of the EESR and LMSR rankings in 2052. The maximum values of these indicators are expected for Norway: EESR equal to 2.0 and LMSR equalling 1.3. The significance of high fertility is demonstrated by France, while the case of Switzerland proves that relatively high labour force participation can, to a large extent, make up for low fertility and resulting unfavourable changes in the population structure.

Southern European countries (Italy, Greece and Spain) demonstrate how far the labour market consequences of the ageing process in Europe can develop over the next 


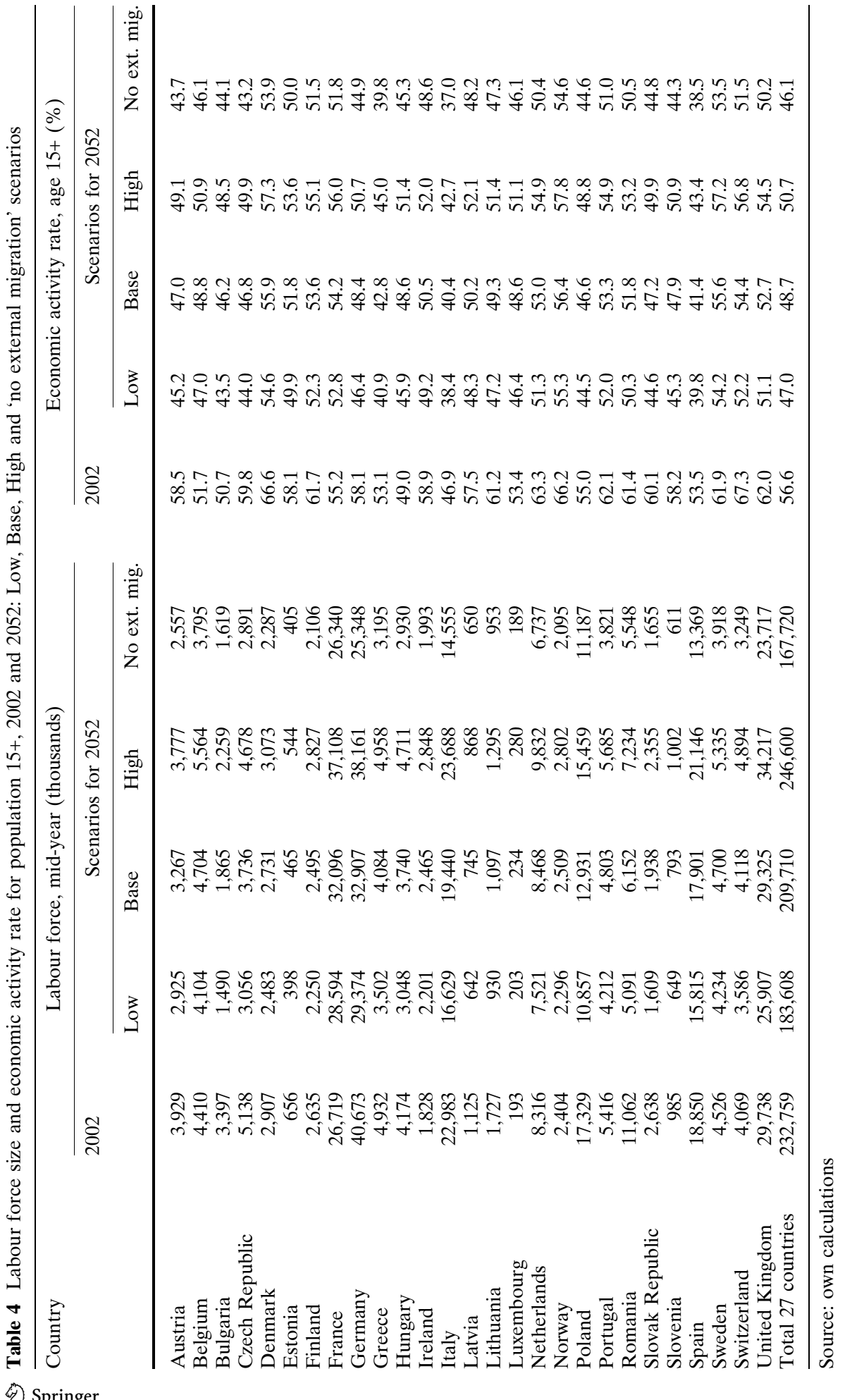


Table 5 Economic Elderly Support Ratio (EESR), Labour Market Support Ratio (LMSR), 2002 and 2052: Low, Base, High and 'no external migration' scenarios

\begin{tabular}{|c|c|c|c|c|c|c|c|c|c|c|}
\hline \multirow[t]{3}{*}{ Country } & \multicolumn{5}{|c|}{ EESR } & \multicolumn{5}{|c|}{ LMSR } \\
\hline & \multirow[t]{2}{*}{2002} & \multicolumn{4}{|c|}{ Scenarios for 2052} & \multirow[t]{2}{*}{2002} & \multicolumn{4}{|c|}{ Scenarios for 2052} \\
\hline & & Low & Base & High & $\begin{array}{l}\text { No ext. } \\
\text { mig. }\end{array}$ & & Low & Base & High & $\begin{array}{l}\text { No ext. } \\
\text { mig. }\end{array}$ \\
\hline Austria & 3.23 & 1.25 & 1.38 & 1.56 & 1.15 & 1.41 & 0.82 & 0.89 & 0.97 & 0.78 \\
\hline Belgium & 2.55 & 1.46 & 1.63 & 1.86 & 1.39 & 1.07 & 0.89 & 0.95 & 1.04 & 0.86 \\
\hline Bulgaria & 2.62 & 1.07 & 1.25 & 1.42 & 1.11 & 1.03 & 0.77 & 0.86 & 0.94 & 0.79 \\
\hline Czech Republic & 3.78 & 1.16 & 1.36 & 1.61 & 1.11 & 1.48 & 0.79 & 0.88 & 0.99 & 0.76 \\
\hline Denmark & 3.92 & 1.83 & 1.97 & 2.15 & 1.75 & 1.99 & 1.20 & 1.27 & 1.34 & 1.17 \\
\hline Estonia & 3.48 & 1.55 & 1.73 & 1.94 & 1.55 & 1.39 & 1.00 & 1.07 & 1.15 & 1.00 \\
\hline Finland & 3.41 & 1.65 & 1.78 & 1.94 & 1.58 & 1.61 & 1.09 & 1.15 & 1.22 & 1.06 \\
\hline France & 2.78 & 1.78 & 1.94 & 2.16 & 1.68 & 1.23 & 1.12 & 1.19 & 1.27 & 1.07 \\
\hline Germany & 2.94 & 1.27 & 1.42 & 1.63 & 1.17 & 1.39 & 0.87 & 0.94 & 1.03 & 0.82 \\
\hline Greece & 2.86 & 1.07 & 1.20 & 1.37 & 1.00 & 1.13 & 0.69 & 0.75 & 0.82 & 0.66 \\
\hline Hungary & 2.72 & 1.34 & 1.56 & 1.85 & 1.29 & 0.96 & 0.85 & 0.95 & 1.06 & 0.83 \\
\hline Ireland & 4.52 & 1.67 & 1.82 & 2.01 & 1.61 & 1.44 & 0.97 & 1.02 & 1.08 & 0.95 \\
\hline Italy & 2.21 & 0.95 & 1.07 & 1.23 & 0.88 & 0.88 & 0.62 & 0.68 & 0.74 & 0.59 \\
\hline Latvia & 3.34 & 1.42 & 1.59 & 1.77 & 1.42 & 1.35 & 0.93 & 1.01 & 1.09 & 0.93 \\
\hline Lithuania & 3.61 & 1.34 & 1.50 & 1.69 & 1.34 & 1.58 & 0.90 & 0.97 & 1.06 & 0.90 \\
\hline Luxembourg & 3.12 & 1.47 & 1.67 & 1.96 & 1.43 & 1.15 & 0.86 & 0.94 & 1.05 & 0.85 \\
\hline Netherlands & 3.88 & 1.67 & 1.84 & 2.07 & 1.59 & 1.72 & 1.05 & 1.13 & 1.22 & 1.02 \\
\hline Norway & 3.82 & 1.87 & 2.00 & 2.18 & 1.79 & 1.96 & 1.24 & 1.30 & 1.37 & 1.20 \\
\hline Poland & 3.83 & 1.20 & 1.35 & 1.53 & 1.20 & 1.22 & 0.80 & 0.87 & 0.95 & 0.81 \\
\hline Portugal & 3.87 & 1.68 & 1.83 & 2.04 & 1.57 & 1.64 & 1.08 & 1.14 & 1.22 & 1.04 \\
\hline Romania & 5.59 & 1.60 & 1.77 & 1.93 & 1.63 & 1.59 & 1.01 & 1.08 & 1.14 & 1.02 \\
\hline Slovak Republic & 4.30 & 1.21 & 1.39 & 1.61 & 1.22 & 1.50 & 0.80 & 0.89 & 1.00 & 0.81 \\
\hline Slovenia & 3.66 & 1.20 & 1.38 & 1.61 & 1.14 & 1.40 & 0.83 & 0.92 & 1.04 & 0.80 \\
\hline Spain & 2.74 & 1.00 & 1.10 & 1.24 & 0.92 & 1.15 & 0.66 & 0.71 & 0.77 & 0.63 \\
\hline Sweden & 3.10 & 1.71 & 1.85 & 2.02 & 1.65 & 1.63 & 1.19 & 1.25 & 1.33 & 1.15 \\
\hline Switzerland & 3.82 & 1.57 & 1.77 & 2.05 & 1.51 & 2.06 & 1.09 & 1.19 & 1.31 & 1.06 \\
\hline United Kingdom & 3.41 & 1.68 & 1.85 & 2.09 & 1.59 & 1.63 & 1.04 & 1.11 & 1.20 & 1.01 \\
\hline Total 27 countries & 3.09 & 1.36 & 1.51 & 1.70 & 1.29 & 1.30 & 0.89 & 0.95 & 1.03 & 0.85 \\
\hline
\end{tabular}

Source: own calculations

50 years. Very low EESR and LMSR values for these countries (in Italy, respectively, 1.07 and 0.68 ) stem from the lowest fertility and economic activity levels in Europe; it is expected that in half a century the share of the active population 15+ in all three countries will be less than $45 \%$. With respect to the high EESR and LMSR values for Romania, it should be kept in mind that the very high economic activity observed especially in the oldest age groups has a different character than in the other countries under study (Saczuk 2004) and thus the results are not directly comparable.

\subsection{High and Low migration scenarios}

In the High scenario the total labour force resources of the 27 countries under study are expected to increase by 6\% (to 247 million) between 2002 and 2052. As a result of the increased number of (young) immigrants from the other parts of the world, the labour force participation rate, equalling $51 \%$, will be slightly higher than in the Base scenario. At the end of the projection period, the post-2002 immigrants and 


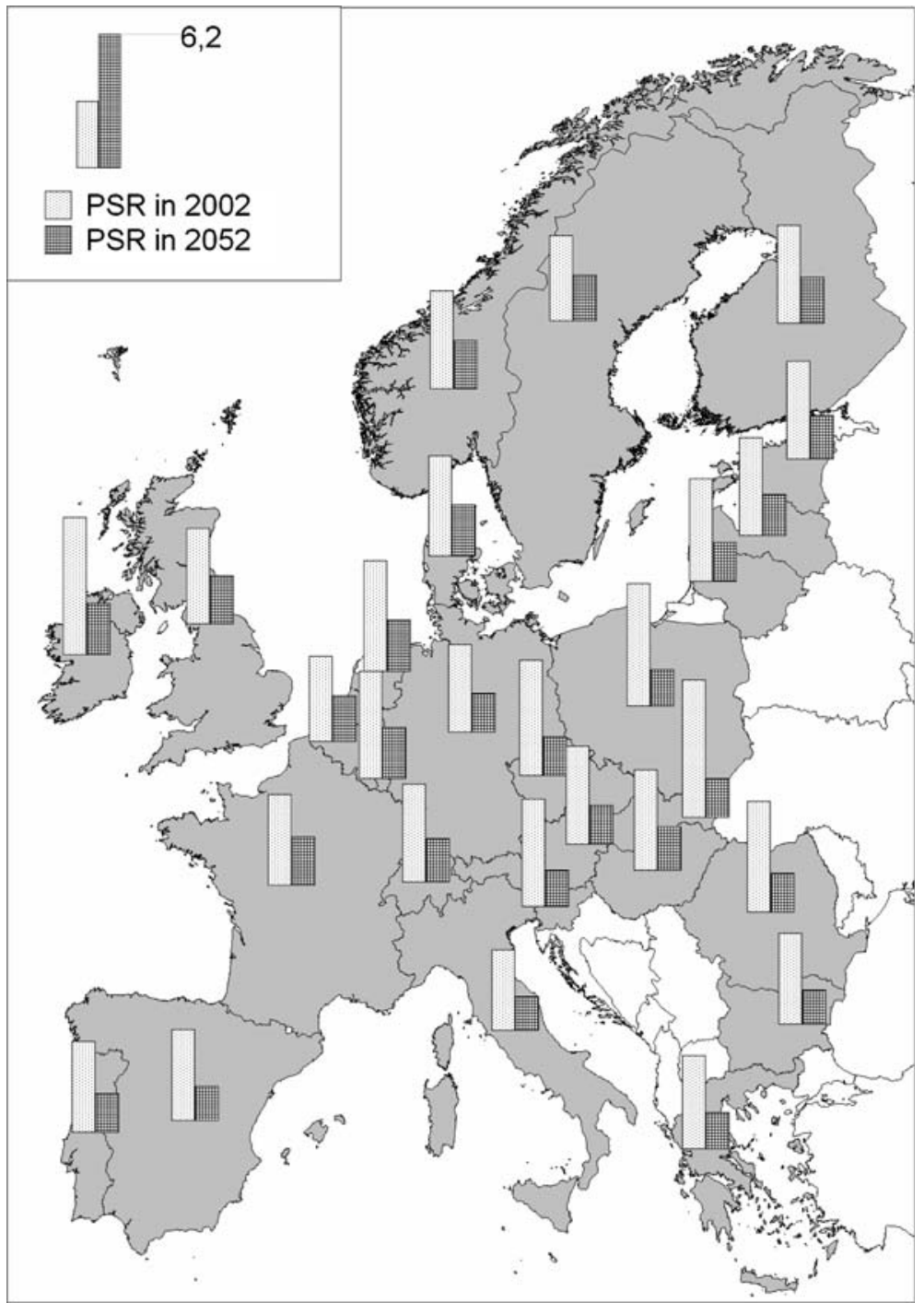

Fig. 2 Potential Support Ratio in 2002 and 2052-Base scenario.

Source-own calculations

their descendants are going to account for almost one-third of the total labour force resources in the 27 European countries.

The assumptions of high immigration do not bring a radical change with respect to population ageing and its effects in comparison to the Base scenario. The ageing process is going to continue, although its economic consequences will be less intense. By 2052, the EESR is going to decline on average to 1.70, while the LMSR will reach 1.03. Not surprisingly, this scenario is going to favour countries with relatively large migration inflows. However, fertility and economic activity still play a dominant role. The highest values of both indicators are reached in Norway and the lowest ones in Italy (see Table 5), similarly as in the Base scenario. 


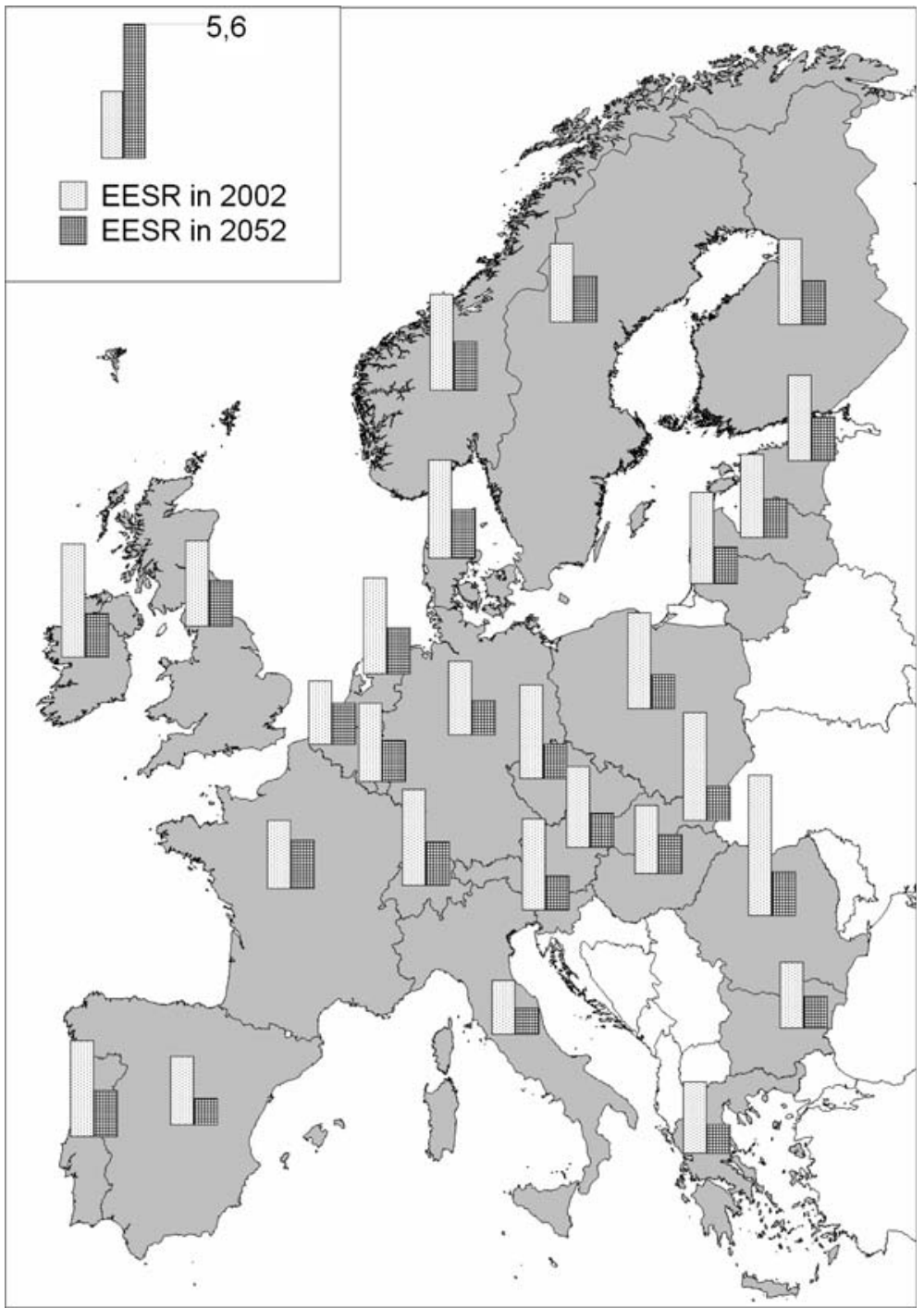

Fig. 3 Economic Elderly Support Ratio in 2002 and 2052-Base scenario.

Source-own calculations

In the Low variant, smaller numbers of immigrants in all age groups, especially the younger ones, influence the projected labour force resources in the opposite direction. At the end of the projection period the overall labour force resources in the 27 countries under study are expected to amount to 184 million people $(21 \%$ less than in 2002), that is $47 \%$ of the total population. The small net inflow of immigrants is going to negatively influence the burden of economically inactive persons on the active population. The average EESR projected for all the countries under study is going to reach 1.36 in 2052, while the average LMSR will be 0.89. Again, the highest values of both indicators projected for 2052 are going to be observed in Norway and 


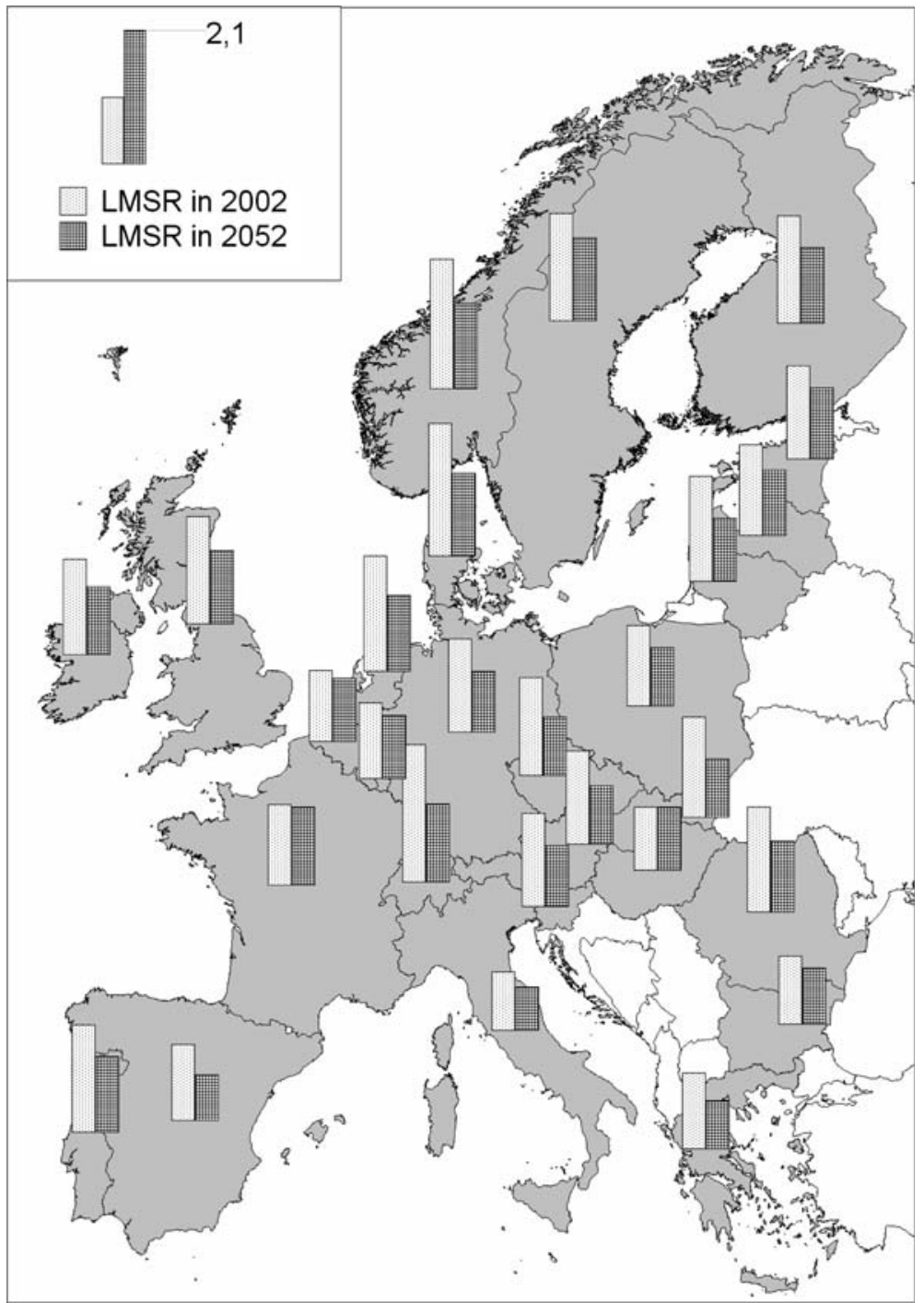

Fig. 4 Labour Market Support Ratio in 2002 and 2052-Base scenario.

Source-own calculations

Denmark, and the lowest ones in Italy and Spain. The country-specific details are provided in Table 5.

5.3 The impact of demographic and economic factors on labour force and activity rates

The post-2002 immigrants and their descendants, who are expected to constitute $20 \%$ of the labour force resources in 2052 in the Base scenario, do not significantly mitigate the effects of the ageing of the labour force. The High and Low projection variants, in our view reflecting the plausible bounds of migration flows to Europe, suggest that 
immigration can alleviate, but not offset, the profound effects of population ageing. The consequences for the European labour markets are twofold: the labour force decreases and is subject to ageing itself, with increasing shares of older age groups in the total labour force. The impact of different migration scenarios on the age structures of the population and the labour force projected for 2052, as well as the background structures observed in 2002 are presented in Fig. 1 in Sect. 4.1.

Analysing changes in labour force participation, we can distinguish the economic and demographic effects. The economic effects reflect the decision of people in particular age groups whether to participate in the labour force or not, while the demographic ones regard the proportions of age groups in the total labour force. In this study, an increase of all age-specific activity rates, most notably for the older groups is assumed. Nonetheless, this is not sufficient to compensate for the ageing of the population in any scenario considered. Hence, in order to keep the overall activity rates at a constant level, more radical changes in the economic activity of the older age groups would be needed.

The declining shares of the labour force in the total population imply a growing burden of the economically inactive population on the active one. In the Base scenario the burden on the pension system per one active person, indicated by its proxy variable, the reciprocal of the EESR, is expected to increase 2.4 times within the next 50 years. In the same period, the per worker overall social security burden (the reciprocal of the LMSR) is going to increase by $59 \%$. A comparison of the EESR and the LMSR dynamics indicates that the increase of the social security burden per one active person is going to stem entirely from the growing number and proportion of pensioners $(65+)$ in the total population. The burden generated by younger age groups (15-64) is expected to slightly decline.

The influence of international migration on these tendencies is again very limited. Within the bounds set by the Low and High projection scenarios, migration has a slight impact on the results (as demonstrated in Table 5), but this effect is not sufficient to compensate for the scale of changes in any of the projection variants. External net immigration results in higher EESR and LMSR values in comparison with the 'zero migration' simulation, but even in the High scenario, with the highest immigration, the EESR and the LMSR are much lower in 2052 than in 2002. The study suggests that high economic activity and, indirectly, high fertility, are more effective and more plausible in mitigating the economic effects of ageing than high immigration.

\subsection{Sensitivity of the results on fertility and labour force participation assumptions}

In addition to the projections presented above, we performed a simple sensitivity analysis of the impact of fertility assumptions. For each country we assumed three additional TFR trajectories: the first one lower than the one originally projected by 0.25 child per woman throughout the period 2002-2052, the second one higher by 0.25 and the third one higher by 0.50 . It has to be noted that these additional trajectories have been derived in a purely mechanical way and do not relate to any particular scenarios-there are no underlying stories behind them. Our aim was simply to specify the plausible lower and upper limits of future fertility changes in the first half of the 21st century. The projected population size and structural indicators obtained under these assumptions (with the remaining projection parameters as in the Base scenario) are shown in Table 6. 


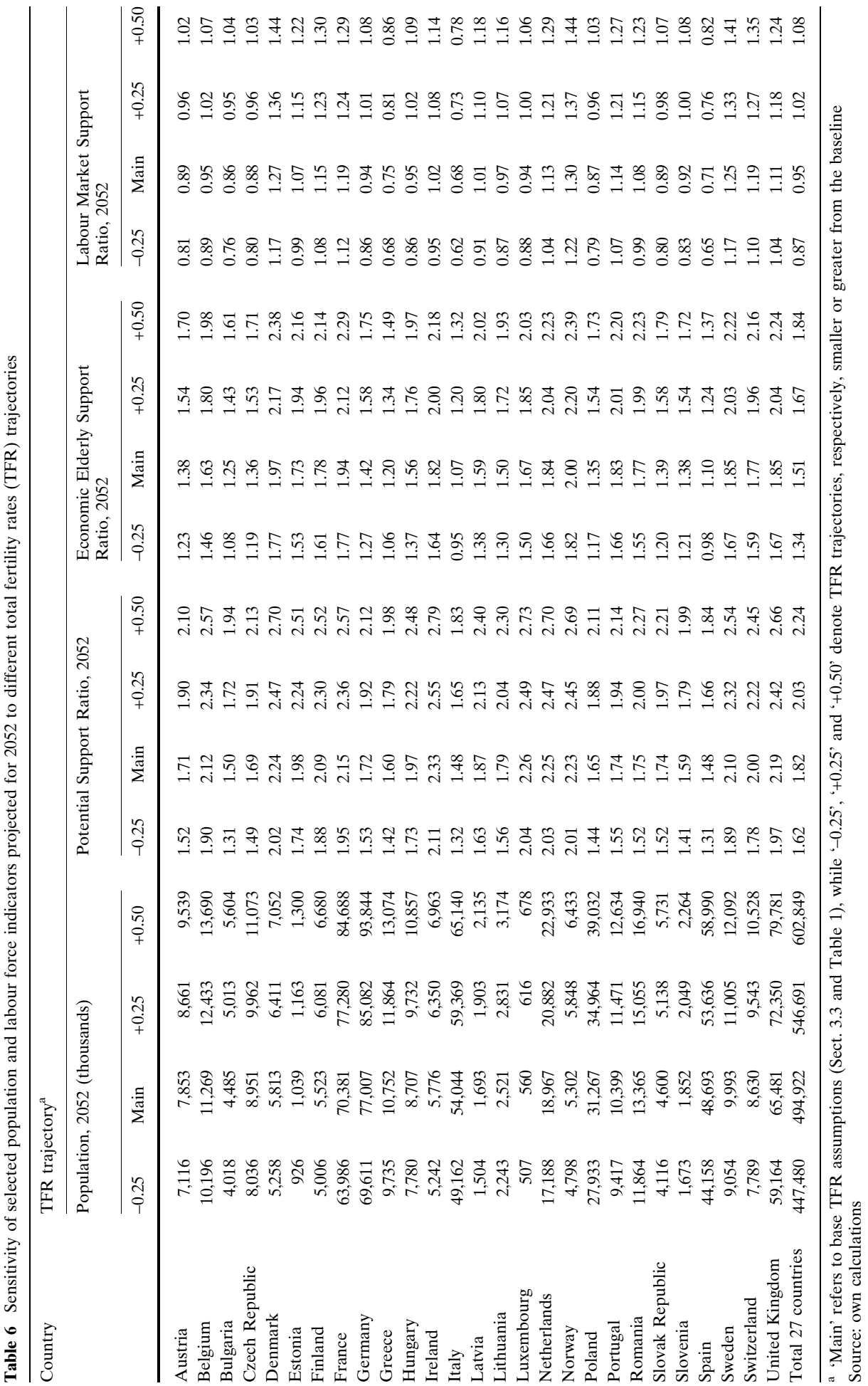


The figures in Table 6, when compared with the ones presented before in Tables 3 and 5, indicate that fertility changes influence the overall population size, but their impact on the structural proxy indicators (the PSR, the EESR and the LMSR) is rather limited. This is especially visible for the low-fertility countries of Southern, Central-Eastern and German-speaking Europe. In all 27 countries even an immediate increase in fertility by 0.50 child per woman, lasting for half a century ahead, would not offset the effects of ageing within this timeframe. The only exceptions with respect to the projected LMSR dynamics are Bulgaria and Hungary, due to the very low initial LMSR values, as well as France, because of the high fertility continuously assumed throughout the projection horizon. Clearly, the assumed changes in reproductive patterns alone are not sufficiently potent to maintain the support ratios for the coming 50 years.

Another simulation was conducted to verify the impact of labour force participation on the economic consequences of ageing, measured by the LMSR. We assumed that over the whole period 2002-2052 the age-specific labour force participation patterns in each country would stay constant, at the maximum levels observed in 1985-2002 in all the countries under study. As a result, in a majority of cases (21 countries), the LMSR would not fall below the values observed in 2002 throughout the projection period. In five countries such a decline would occur only in the 2040s (Czech Republic, the Netherlands, Portugal, Slovak Republic and Spain). Only in Switzerland, would the LMSR drop below its 2002 value already in the mid-2020s, due to high initial levels of economic activity. This exercise shows that an increased labour force participation can offset some labour market sideeffects of population ageing, at least within a couple of decades.

\section{Summary and conclusions}

This study had two main objectives: to project European populations and labour force resources for the coming 50 years and to assess the impact of plausible migration flows on the effects of ageing with respect to the aggregate indicators of social security and labour market burdens. The latter seems important, as given the existing zero or negative natural population growth in many European countries, international migration already now contributes substantially to the vitality of European populations.

There are a lot of studies, including this one, showing that ageing in Europe and declining populations in some European countries either are or will become important, if not overwhelming, phenomena. We agree with Coleman (2004) that maintaining the population size does not seem to be a valid aim of population policy. However, Europe is going to face structural changes requiring a modification of the financing of social security systems, provision of services and a reshaping of many aspects of the functioning of the societies. As in many countries the demographic change results in a declining number of workers and an increasing number of retired, the pay-as-you-go pension system will soon become impossible to manage.

The comparison of the aggregate indicators for 2002 and 2052 shows that higher immigration and higher economic activity can slow the negative economic consequences of the ageing process down. It is evident, however, that only a combination of both, ideally with an increased fertility, can bring the most promising results. With respect to immigration alone, in order to keep the population structure of Europe 
relatively young, many more immigrants would theoretically be needed than it is currently assumed in the High variant of the projection, seen as the high bound of the possible future immigration size (see also the simulations by the United Nations 2000; Feld 2000; Bijak et al. 2005). The weak sensitivity of the results to fertility changes indicates that fertility alone is not omnipotent in offsetting the consequences of population ageing either, at least within the timeframe of the coming 50 years.

The projections show that the long-term consequences of demographic change should be treated by social policy-makers and politicians whose temporal perspective exceeds the nearest election, with due attention. The changes in social policies aiming at an increase in fertility, increase in labour force participation and reforms of pension systems are at the core of the strategies for the adaptation of social and economic systems to the new demographic patterns. Demographic change cannot be tackled with marginal or partial reforms. On the contrary, the reforms needed to compensate the population decline and ageing will be painful, will affect the entire populations and will reshape the social situation of the next generations.

The results also confirm the diversity of demographic and economic activity patterns in Europe: policy challenges related to ageing and its labour market consequences are not expected to be very dramatic in Scandinavia, but they are going to be profound in the South. Especially in countries like Greece, Italy and Spain, a combination of low fertility and low labour force participation may be very unfavourable in the long run. Out of the menu of basic possible policies aimed at meeting the challenges posed by ageing (i.e. increased fertility, economic activity and immigration), the combinations chosen by particular countries should take this diversity into account, as there is no universal solution. For example, Southern European countries should primarily focus on increasing fertility and economic activity, Central Europe on fertility, economic activity and, to some extent, immigration, while for the German-speaking countries fertility comes in the first place. Although the determination of the optimal combinations of policies for particular countries remains beyond the scope of the current study, it would definitely be worth addressing in separate research. Nevertheless, such analysis should take additional constraining factors into account, especially with respect to migration. For example, the actual demand for foreign labour, as well as sensitive social and political issues should be considered (Coleman 2004).

As it has been noted by LaLonde and Topel (2003), most of the existing empirical research on the effects of international population flows on the labour markets primarily concerns Australia, Canada and the United States. Therefore, although the findings of the current analysis are in general not very novel, we made an attempt to partially fill the mentioned gap and to perform an analysis of interrelations between migration and labour force for a diversity of European countries. In this way, we wanted to contribute to the debate about population ageing and the possible demographic policy options from an European perspective. Regardless of our contribution, much more empirical research on this and related topics is still necessary in Europe in order to address one of the key policy challenges of the 21st century.

Acknowledgements Central European Forum for Migration Research (CEFMR) is a research partnership of the Foundation for Population, Migration and Environment (BMU-PME) of Zurich, Institute of Geography and Spatial Organization of the Polish Academy of Sciences and International Organization for Migration, managed by the Warsaw Office of the latter. This paper contains 
partial results of the project Impact of international migration on population dynamics and labour force resources in Europe, conducted by the CEFMR and financed by the BMU-PME Foundation. Jakub Bijak also benefited from the Foundation for Polish Science Stipend for Young Scientists. The authors are very grateful to two anonymous referees for valuable comments that helped to improve the paper. All the remaining errors are ours.

\section{References}

Augusztinovics, M. (1999). Pension systems and reforms in the transition economies. In Economic survey of Europe 1999, no. 3 (pp. 89-114). Geneva: United Nations Economic Commission for Europe, with discussion.

Becker, G. S. (1991). A treatise on the family. Cambridge: Harvard University Press.

Bijak, J. (2004). Fertility and mortality scenarios for 27 European countries, CEFMR working paper 3/2004. Warsaw: CEFMR.

Bijak, J., Kupiszewska, D., Kupiszewski, M., \& Saczuk, K. (2005). Impact of international migration scenarios on population dynamics and labour force resources in Europe, CEFMR working paper 1/2005. Warsaw: CEFMR.

Bijak, J., Kupiszewski, M., \& Kicinger, A. (2004). International migration scenarios for 27 European countries, CEFMR working paper 4/2004. Warsaw: CEFMR.

Christensen, K., \& Vaupel, J. W. (1996) Determinants of longevity: genetic, environmental and medical factors. Journal of Internal Medicine, 240, 333-341.

Coleman, D. A. (1992). Does Europe need immigrants? Population and work force projections. International Migration Review, 26, 413-461.

Coleman, D. A. (2002). Replacement migration, or why everyone is going to have to live in Korea: a fable for our times from the United Nations. Philosophical Transactions of the Royal Society B, 357, 583-598.

Coleman, D. A. (2004). Europe at the cross-roads - must Europe's population and workforce depend on new migration? In: V. Iontsev (Ed.), International migration: ICPD +10 , scientific series "International migration of population: Russia and contemporary world" (Vol. 12, pp. 19-33). Moscow: Max.

DFA. (2005). The EU extension and the extension of the Agreement on the free movement of persons. Available from www.europa.admin.ch, status as of 18 July 2005. Bern: Swiss Integration Office.

Easterlin, R. A. (1968). Population, labor force, and long swings in economic growth. New York: National Bureau of Economic Research.

Espenshade, T. J. (2001). "Replacement migration” from the perspective of equilibrium stationary populations. Population and Environment, 22, 383-400.

Espenshade, T. J., Bouvier, L. F., \& Arthur, W. B. (1982). Immigration and the stable population model. Demography, 19, 125-133.

European Commission. (2003). The rationale of motherhood choices: influences of employment conditions and of public policies, research report. Luxembourg: European Commission.

European Commission. (2005). Green paper "confronting demographic change: a new solidarity between the generations", COM (2005) 94 final. Brussels: European Commission.

European Commission. (2006). Report on the functioning of the transitional arrangements set out in the 2003 accession treaty (period 1 May 2004-30 April 2006), COM (2006) 48 final. Brussels: European Commission.

European Communities. (2002). Agreement between the European Community and its Member Sates, of the one part, and the Swiss Confederation, of the other, on the free movement of persons, OJ L 114 of 30 April 2002.

European Communities. (2003). Treaty concerning the accession of the Czech Republic, the Republic of Estonia, the Republic of Cyprus, the Republic of Latvia, the Republic of Lithuania, the Republic of Hungary, the Republic of Malta, the Republic of Poland, the Republic of Slovenia and the Slovak Republic to the European Union, OJ C 227E of 23 September 2003.

European Communities. (2005). Treaty concerning the accession of the Republic of Bulgaria and Romania to the European Union, OJ L 157 of 21 June 2005.

Eurostat. (2005). Population projections 2004-2050. Available from epp.eurostat.cec.eu.int, status as of 15 April 2005. Luxembourg: Eurostat.

Feld, S. (2000). Active population growth and immigration hypotheses in Western Europe. European Journal of Population, 16, 3-40. 
Grant, J., Hoorens, S., Sivadasan, S., van het Loo, M., DaVanzo, J., Hale, L., Gibson, S., \& Butz, W. (2004). Low fertility and population ageing. Causes, consequences and policy options. Santa Monica: RAND Corporation.

Green, A. E, Owen, D. W., \& Wilson, R. A. (2001). Regional labour force differences among young people in the European Union, Eurostat working paper 3/2001/E/no. 7. Luxembourg: Eurostat.

International Labour Organisation. (2004). LABORSTA database on labour statistics. Available from laborsta.ilo.org, status as of 1 November 2004.

Jennissen, R. (2004). Macro-economic determinants of international migration in Europe, population studies series. Amsterdam: Dutch University Press.

van de Kaa, D. J. (2003). Demographics in transition: an essay on continuity and discontinuity in value change. In I. E. Kotowska, \& J. Jóźwiak, (Eds.), Population of Central and Eastern Europe: challenges and opportunities (pp. 641-663). Warsaw: Statistical Publishing Establishment.

Korcelli, P. (2003). Migracje kompensacyjne a kształtowanie podstaw polskiej polityki imigracyjnej. In Polska $i$ Europa. Kształtowanie przestrzeni wolności. Europa XXI (Vol. 9, pp. 143-151). Warsaw: Institute of Geography and Spatial Organization, Polish Academy of Sciences (in Polish).

Kotowska, I. E. (2003). Older workers in the labour market, retirement policies. In R. Palomba, \& I. E. Kotowska (Eds.), The economically active population in Europe, Population studies 40. (pp. 55-93) Strasbourg: Council of Europe.

Kulu, H. (2005). Migration and fertility: competing hypotheses re-examined. European Journal of Population, 21, 51-87.

Kupiszewska, D., \& Kupiszewski, M. (2005). A revision of traditional multiregional model to better capture international migration: the MULTIPOLES model and its application, CEFMR working paper 10/2005. Warsaw: CEFMR.

Kupiszewski, M. (2002). Modelowanie dynamiki przemian ludności w warunkach wzrostu znaczenia migracji międzynarodowych. Warsaw: Institute of Geography and Spatial Organization, Polish Academy of Sciences.

Kupiszewski, M., \& Kupiszewska, D. (1998). Projection of Central and East European populations-models, data, preliminary results. In J. Fleischhacker, \& R. Münz (Eds.), Gesellschaft und Bevölkerung in Mittel- und Osteuropa im Umbruch, Demographie Aktuell 13. (pp. 22-40). Berlin: Humboldt Universität.

LaLonde, R. J., \& Topel, R. H. (2003). Economic impact of international migration and the economic performance of migrants. In M. R. Rosenzweig, \& O. Stark (Eds.), Handbook of population and family economics (Vol. 1B, pp. 799-850). Amsterdam: Elsevier.

Lesthaeghe, R. (2000). Europe's demographic issues: fertility, household formation and replacement migration, paper for the expert group meeting on policy responses to population ageing and population decline, 16-18 October. New York: United Nations Population Division.

Lesthaeghe, R., \& van de Kaa, D. J. (1986). Twee demografische transities? In D. J. van de Kaa, \& R. Lesthaeghe, (Eds.), Bevolking: Groei en Krimp. (pp. 9-24). Deventer: Van Loghum Slaterus.

Liefbroer, A. C., \& Corijn, M. (1999). Who, what, where, and when? Specifying the impact of educational attainment and labour force participation on family formation. European Journal of Population, 15, 45-75.

Meslé, F. (2004). Mortality in Central and Eastern Europe: long-term trends and recent upturns, Demographic Research, special collection 2, 45-70. Available from www.demographicresearch.org, status as of 18 July 2005.

Muszyńska, M. (2006). Structural and cultural determinants of fertility in Europe. Ph.D. thesis. Warsaw: Warsaw School of Economics.

National Research Council. (2001). Preparing for an aging world: the case for cross-national research. Washington: National Academy.

OECD. (2005). Glossary of statistical terms. Available from stats.oecd.org/glossary, status as of 15 December 2005.

Oeppen, J., \& Vaupel, J. W. (2002). Demography: broken limits to life expectancy. Science, 296, 1029-1031.

Olshansky, S. J., Carnes, B. A., \& Cassel, C. (1990). In search of Methuselah: estimating the upper limits to human longevity. Science, 250, 634-640.

Pollard, J. H. (1973). Mathematical models for the growth of human populations. Cambridge: Cambridge University Press.

Productivity Commission. (2005). Economic implications of an ageing Australia, Productivity Commission research report. Melbourne: Productivity Commission. 
Rees, P. H. (1996). Projecting national and regional populations of the European Union using migration information. In: P. H. Rees, J. S. C. Stillwell, A. Convey, \& M. Kupiszewski, (Eds.), Population migration in the European Union. (pp. 330-364). Chichester: Wiley.

Rees, P. H., Stillwell, J. S. C., \& Convey, A. (1992). Intra-community migration and its impact on the development of the demographic structure at regional level. School of Geography working paper 92/1. Leeds: University of Leeds.

Rees, P. H., \& Willekens, F. (1981). Data bases and accounting frameworks for IIASA's comparative migration and settlement study, collaborative paper CP-81-39. Laxenburg: IIASA.

Rogers, A. (1975). Introduction to multiregional mathematical demography. New York: Wiley.

Roseveare, D., Leibniz, W., Fore, D., \& Wurzel, E. (1996). Ageing populations, pensions systems and government budgets: simulations for 20 OECD countries. OECD Economics Department working papers 168 . Paris: OECD.

Saczuk, K. (2003). Development and critique of the concept of replacement migration. CEFMR working paper 4/2003. Warsaw: CEFMR.

Saczuk, K. (2004). Labour force participation scenarios for 27 European countries. CEFMR working paper 5/2004. Warsaw: CEFMR.

Sobotka, T. (2004). Postponement of childbearing and low fertility in Europe. Population studies series. Amsterdam: Dutch University Press.

Taylor, J. (2003). Aboriginal population profiles for development planning in the Northern East Kimberley. Research monograph no. 23, Centre for Aboriginal Economic Policy Research. Canberra: The Australian National University.

Tomorrow's Company. (2005). The ageing population, pensions and wealth creation. London: Tomorrow's Company.

UN ECE [United Nations Economic Commission for Europe]. (1999). Demographic ageing and the reform of pension systems in the ECE region. Papers from the ECE Spring seminar, May 1999: introduction and summary of discussion. In Economic Survey of Europe 1999, no. 3 (pp. 45-56). Geneva: United Nations Economic Commission for Europe.

United Nations. (2000). Replacement migration: is it a solution to declining and ageing populations? New York: United Nations Population Division.

United Nations. (2002). World population ageing: 1950-2050. New York: United Nations Population Division.

United Nations. (2005). World population prospects: 2004 revision. New York: United Nations Population Division.

US Census Bureau. (2004). Global population profile: 2002, international population reports WP/02. Washington: US Government Printing Office.

World Bank. (2005). World Bank demographic projections. On-line resource available from: devdata.worldbank.org/hnpstats/dp.asp, status as of 18 July 2005. 